UC-20

Reporting Date: June 1974 lesued: August 1974

\title{
A Transformer for Injection Experiments
}

by

Richord E. Blemon

\section{sciontifle laboratory}

of the University of Cellfornie

los alAmos, NEW MEXICO 87544<smiles></smiles> 
This report was prepared as an account of work sponsored by the United States Government. Neither the United States nor the United States Atomic Energy Commission, nor any of their employes, nor any of their contractors, subcontrectors, or their employees, makes any warranty, expres or im. plied, or exumes eny legal liability or responsibility for the accuracy, com. pleteness or usefulness of any information, spnuratus, product or process disclosed, or represents that its use would not infringe privately owned rights.

In the interest of prompt distribution, this LAMS report was not edited by the Technical Information staff.

Printed in the United States of America. Available trom National Technical Information Sorvice

U.S. Department of Commerce 5285 Port Royal Road Springtield, Virginia 22151

Price: Printed Copy \$4.00 Microfiche \$1.45 


\section{A TRANSFORMER FOR INJECT:ON EXPERIFENTS}

by

Richard E. Siemon

\section{ABSTRACT}

This report describes an air-core transformer designed to provide a slow rising field in a single-turn col2. The primary, driven by available 10-kv capacitors, carries a relatively small current $(\sim 200 \mathrm{kA})$, while the secondary carries a large current (over $4 \mathrm{HA}$ ). Although the efficlency 18 modeat (about 20\%), the transformer gives the proper rise time and the small primary current requires few switches and cabies in the capacitor bank.

\section{INTRODUCTION}

For infection experiments, one desires a magnetic fileld, varying slowly in time, with the same magnitude as the rapidly pulsed fields in adjacent coll sections!,2 The conventional theta-pinch single-turn call is conventent to fabricate, and helical fielis can be created when tts inner surface is shaped. However, the low Inductance of a single-turn coll is not convenient fur use with the low voltage Zeus capacitors available to power the injected region. Therefore, a transformer has been designed to permit a better impetance match.

\section{TRANSFCRAER DESIGN}

A. Geometry Parameters. Figure 1 shows the various geometrical parameters needed in the design. The coll is shown in Figure 2.

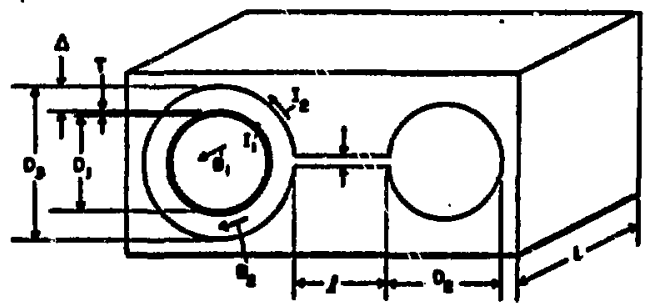

Figure 1. Transformer with singlewturn secondary. $D_{3}=D_{1}+2 \Delta+2 T$.

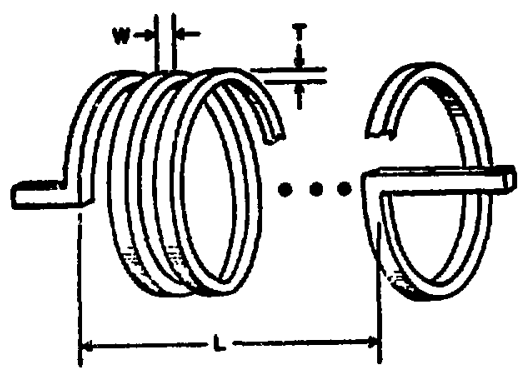

Figure 2. Primary coll with $n$ turns. $W=L /(n+1)$.

\section{B. Yaxwe11's Equations.}

As an approximation, we assume the $B$ flelds are everywhere straight and uniform with $B_{2}-B_{1}$ given by the current in the coll. $B_{2}$ is the seme outside the coll and inside $\mathrm{D}_{2}$.

$$
\begin{aligned}
& \text { From } \nabla \times E=-\frac{\partial B}{\partial t} \\
& \text { or conclude } \quad I_{2} R_{2}+\dot{B}_{1} A_{1}+\dot{B}_{2} A_{2}=0 \\
& V_{c o 11}=I_{1} R_{1}+n B_{1} A_{1}
\end{aligned}
$$


where $I_{2}=$ current in secondary (collector plate)

$R_{2}=$ resistance in secondary

$A_{1}=\operatorname{sod}_{1}^{2} / 4$

$A_{2}=\pi D_{3}^{2} / 4+\pi D_{2}^{2} / 4+\ell t-\pi\left(D_{1}+2 T\right)^{2} / 4$

$A_{2}=$ area outside coll but inside secondary.

From $\nabla \times B=\mu_{0} J$

$$
\begin{aligned}
& B_{1}-B_{2}=\frac{\mu_{0} I_{1} n}{L} \\
& B_{2}=\frac{\mu_{0} I_{2}}{I}
\end{aligned}
$$

These can be rearranged as follown:

$$
\begin{aligned}
& \dot{B}_{2}=\frac{\mu_{0} \dot{I}_{2}}{L} \\
& \dot{B}_{1}=\frac{\mu_{0}}{L}\left(n t_{1}+\dot{I}_{2}\right) \\
& I_{2} R_{2}+\frac{\mu_{0}{ }^{n}}{L} \dot{I}_{1} A_{1}+\frac{\mu_{0} I_{2}}{L} A_{1}+\frac{\mu_{0} A_{2}}{L} \dot{I}_{2}=0 \\
& V_{c o 11}=I_{1} R_{1}+\dot{I}_{1}\left(\frac{\mu_{0}{ }^{2} A_{1}}{L}\right)+\dot{I}_{2}\left(\frac{n A_{1} \mu_{0}}{L}\right) \\
& I_{2} R_{2}+I_{1}\left(\frac{\mu_{0} n A_{1}}{L}\right)+\dot{I}_{2} \frac{\mu_{0}}{L}\left(A_{1}+A_{2}\right)=0
\end{aligned}
$$

In the low resiatance 11 mit, $I_{2} R_{2}$ can be considered small compored to the other terma in equation (6). In that case

$$
\frac{I_{1}}{I_{2}}=-\frac{A_{1}+A_{2}}{n_{2}} \text {. }
$$

We have an effective turne ratio m

$$
\begin{aligned}
& m=\frac{m A_{1}}{A_{1}+A_{2}}, \\
& I_{2}=-m I_{1} .
\end{aligned}
$$

From equation (6)

$$
\dot{I}_{2} \frac{\mu_{0} \mathrm{nA}}{L}=-\dot{I}_{1} \frac{\mu_{0} \mathrm{nmA}}{L}+m^{2} R_{2} I_{1} .
$$

Prom equation (5)

$$
v_{c o 11}=\frac{H_{0} n^{2} A_{1}}{I}\left(\frac{A_{2}}{A_{1}+A_{2}}\right) I_{1}+I_{1}\left(R_{1}+m^{2} K_{2}\right) .
$$

\section{c. Circult Parameters.}

In this approximation, we see that the coll has an effective irductance and resistance:

$$
L_{\text {eff }}=\frac{\mu_{0} n^{2} A_{1}}{L} \frac{A_{2}}{A_{1}+A_{2}}=\frac{\mu_{0} m A_{2}}{L}
$$

$$
R_{\text {eff }}=R_{1}+m^{2} R_{2} \text {. }
$$

We now lmagine connecting the effective coll to a capacitor bank with inftial charge $v_{0}$, capacitance $c$, Inductance $b_{b}$, realstance $R_{b}$, and ask for the efficiency of transfer from $1 / 2 \mathrm{CV}_{0}{ }^{2}$ to magnetIc energy in the bore $\mathrm{D}_{2}$

$$
\epsilon \equiv \frac{1 / 2 \mathrm{~L}_{c} \mathrm{I}_{2}^{2}(\max )}{1 / 2 \mathrm{Cv}_{0}^{2}}
$$$$
\text { where } \quad L_{c}=\frac{\mu_{0} \pi D_{2}^{2}}{4 \mathrm{~L}} \text {. }
$$

This oimple R-LaC circult has a current given by

$$
I_{1}=\frac{v_{0}}{w_{n} L} e^{-\alpha t} \sin w_{n} t
$$

where $w_{n}=\sqrt{w_{0}^{2}-\alpha^{2}}$

$\omega_{0}^{2}=1 / L C$

$\alpha=R / 2 L$

$$
R=R_{\text {eff }}+R_{b}
$$

$$
L=L_{\text {eff }}+L_{b}
$$

The current maximum comes at $t_{m}$ where

$$
t_{m}=\frac{1}{w_{n}} \tan ^{-1}\left(w_{n} / \alpha\right) \text {. }
$$


When $\alpha^{2}>\omega_{0}^{2}$ we rewrite these as

$$
\begin{aligned}
& I_{1}=\frac{v_{0}}{w_{n} I} e^{-\alpha t} \sinh \left(\omega_{n} t\right) \\
& t_{m}=\frac{1}{2 \omega_{n}} \ln \left(\frac{\alpha+\omega_{n}}{\alpha-\omega_{n}}\right) .
\end{aligned}
$$

To evaluate these formulas, we need expressions for $R_{1}$ and $R_{2}$ which we obtain by assuming all the cirrent flows in $8 / 2$ where $\delta$ is the classical skin depth and the Erequency $18 \omega_{0}$

$$
\begin{aligned}
& \delta=\sqrt{2 \epsilon_{0} c^{2} / \sigma \omega_{0}}=\sqrt{\frac{2}{\mu \sigma \omega_{o}}} \\
& \epsilon_{0} c^{2}=\frac{10^{7}}{4 \pi}=\frac{1}{\mu_{0}} \\
& \sigma_{\text {a lum }}=3.5 \times 10^{7} \text { who/meter } \\
& \sigma_{\text {copper }}=5.7 \times 10^{7}
\end{aligned}
$$

We will take $R_{1}$ to be the bank resistance plus the resistance of the coil plus one $m \Omega$ to allow for lead resistance, and we w111 assume that a copper strap is used to fabricate a coll filling the avallable space. Then

$$
\begin{aligned}
& R_{\text {col } 1}=\frac{(\text { leng }, i s)}{\sigma(\text { Area })} \\
& \text { Area }=(6 / 2) W-(6 / 2)\left(\frac{L}{n+1}\right) \\
& \text { Length }=n \pi\left(D_{1}+T\right) \\
& R_{1}=R_{c o 11}+R_{b}+.001 \\
& R_{1}=\frac{2 n(n+1) \pi\left(D_{1}+T\right)}{\sigma_{C u}{ }_{C u} L}+R_{b}+.001 .(16)
\end{aligned}
$$

\begin{tabular}{|c|c|c|c|}
\hline Given & FoRTRAY Symbol & Celculate & PorTRAN Symbol \\
\hline$D_{1}(a)$ & DI & $\varepsilon$ & EFS \\
\hline$D_{2}(m)$ & D2 & $I_{1}\left(t_{n}\right)(x A)$ & XII \\
\hline$\Delta(m)$ & Do & $I_{2}\left(t_{-1}\right)(x)$ & $\mathbf{X I 2}$ \\
\hline & & $B_{1}(B-\theta)$ & B1 \\
\hline$l(0)$ & $\boldsymbol{x u}$ & $b_{2}(x)$ & $\mathbf{B 2}$ \\
\hline$I(D)$ & $x 12$ & $R_{1}(n)$ & $\mathbf{R 1}$ \\
\hline D & $20 \mathrm{~s}$ & $=^{2} R_{2}(=0)$ & $\mathbf{E R 2}$ \\
\hline I & THI & $t=(\mu s)$ & III \\
\hline$c(-)$ & THi2 & & \\
\hline$c(4)$ & c & $\alpha$ & AlP \\
\hline$v_{0}(n v)$ & $\nabla$ & $8_{A 1}(\square)$ & DesLl \\
\hline$\pi_{b}(n n)$ & Ro & $L_{\text {eff }}(\mu h)$ & Em \\
\hline$L_{b}(n h)$ & xL & $B_{\Lambda 2}\left(w_{n}\right)(\square)$ & $\mathbf{X T}$ \\
\hline
\end{tabular}

For $\mathrm{A}_{2}$ we have

$$
R_{2}=\frac{2 \ell+\pi D_{3}+\pi D_{2}}{\sigma_{A 1} L\left(\sigma_{A 1} / 2\right)}
$$

D. Numerical Results.

With equations (1) through (17), we take certain parameters as given and calculate the remaining parameters is follows:
A. FORTRAN program was written to carry out this calculation. For 8 given $n, D_{1}$ tras varied to determine the maximum efficiency. The capacitance and $\nabla_{\sigma}$, aval lable in two racks of Zeus capacitors (192 capacitors), were chosen for the bank. We assume that for the Zeus capacitor $8, a$ "shel.f" of 48 capacitors has the following characteristics;

$$
\begin{aligned}
& c=48 \times 62=2976 \mu \mathrm{F} \\
& v_{\max }=10.0 \mathrm{kV} \\
& \mathrm{u}_{b}=26 \mathrm{nH} \\
& \mathrm{R}_{b}=0.9 \mathrm{~m} \Omega .
\end{aligned}
$$

We estimate a bank of 192 capacitors to have

$$
\begin{aligned}
& c=11,904 \mu \mathrm{f} \\
& L_{b}=6.5 \mathrm{nH} \\
& R_{b}=.225 \mathrm{~m} \Omega .
\end{aligned}
$$

Results for typilcal case are given in pigures 3-5. Input parameters were the following (see Append $1 x$ ): 
Input

$\mathrm{n}_{2} .11 \mathrm{~m}$ (large bore) or .0635 m (8mall bore)

$8 \quad 4 \mathrm{~mm}$

l. $3 \mathrm{~m}$

L $\quad 1.0 \mathrm{~m}$

T $\quad 6.0 \mathrm{~mm}$

t $\quad 3.0 \mathrm{~mm}$

C $11,904, \mu f$

$v_{0} \quad 9.7 \mathrm{kt}$

R. $\quad .225 \mathrm{~m} \mathrm{R}$

Ib $\quad 6.5 \mathrm{nfl}$

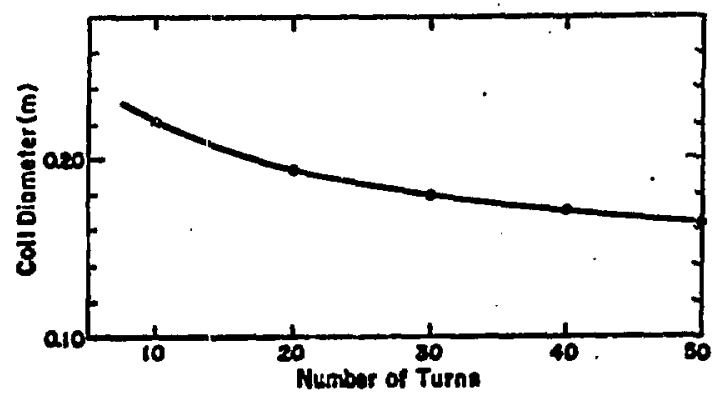

Pigure 3. Coll diameter for maximim efficiency as a function of a aseuning $D_{2}=.11 \mathrm{a}$.

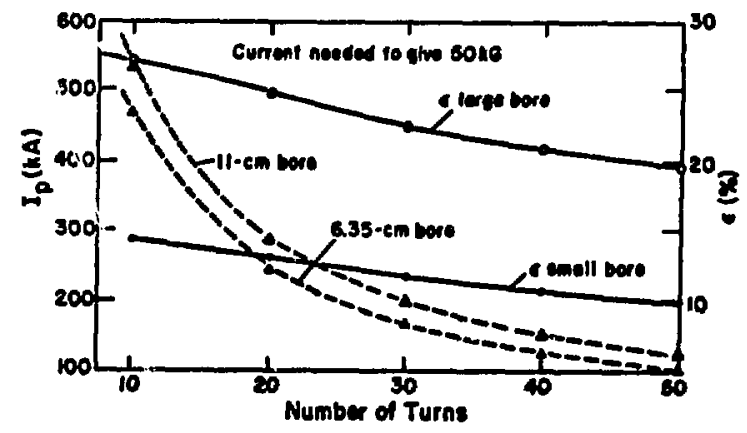

Pigure 4. Pi-imary current required to produce $50 \mathrm{kG}$ (on lef:) and efficiency (on right) at functions of $n$ for $D_{2}=.12=$ (lerge bore) and $D_{2}=.0635 \mathrm{~m}$ ( $\cos 11$ bore).

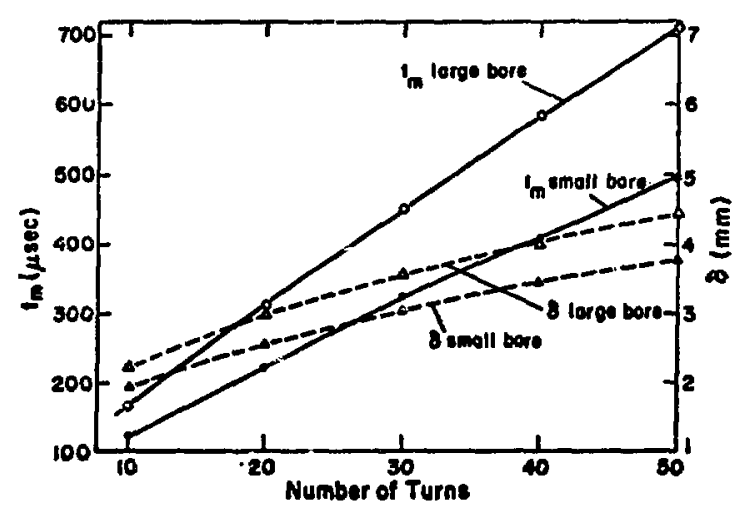

Figure 5. The time of theld maximum (on left) and the skin depth in cluminium (on right) as a function of $n$ and large or mall bore.

The coll diaweter ahown in Figure 3 vas calculated to give anximm efficiency as a function on $n$ in the large bore case. The aare coll diameter gives a lower efficlency in the amil bore but it 1s adequate for the areller energy needed.

Figure 4 gives the primary current needed to obtain $50 \mathrm{kG}$, and the tranafer efficiency as defined above. Pigure 5 givee the time to field maximu, $t_{m}$, and the okin depth in aluminum.

The rather 10 efficiencles (20\% or so) are due to: 1) efgnificant realatance which absorbs about $60 \%$ of the Inttial energy, and 2) ares effecte (uselese flux) which waste about $20 \%$ of the Initial energy.

The anin advanteges to tha use of a tranoformer. rather than direct coupling fros the capacitor bank coll are the following: 1) the rise tim becomes long, 2) the current frou the capecitore (primery current) 10 onil, 3) not man witches are needed eince the current is om 11, and 4) not mny cables are needed since the current it and1.

\section{HCAHOWLDEREMS}

Thlo work was guldad by Eduln torp and ueaful corcente were recetved from John wrahall, Robin Gribble, and Warren Quinn. Kamath Banke is dolng the detelled mechenical desifn. 
APPENDLX

MODIFLED DESIGN

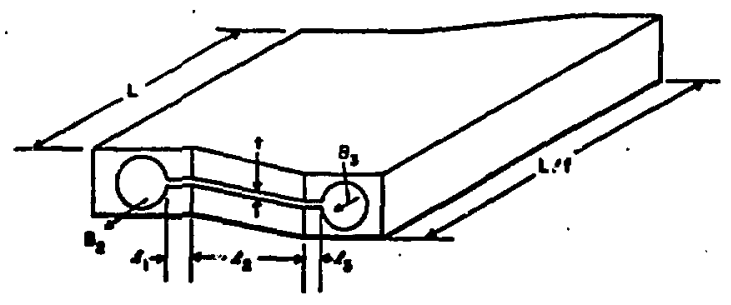

Figure 6. Wodified deilgn needed to fit transforwer and comections between adjacent theta-pinch collector plates.

For the final dealgn, a shape like that shown In Figure 6 was chosen. In that case, $\mathrm{h}_{2}$ must be calculated as the sum of areas which are velghted according to the local $B$ field. $B_{2}$ is the field outalde the winding and $B_{3}=f B_{2}$ is the Eleld inalde bore $\mathrm{D}_{2}$.

The following formulas anet be modified:

$$
\begin{aligned}
& A_{2}=\pi_{3}^{2} / 4-\pi\left(D_{2}+2 \pi\right)^{2} / 4+l_{1}+l_{2} t\left(\frac{1+f}{2}\right)+f l_{3} t+f \pi_{2}^{2} / 4 \\
& \left.R_{2}=\left(2 / \sigma_{A 1} I \delta_{A 1}\right) \mid 2 l_{1}+\pi D_{3}+\frac{4 l_{2} f}{f+1}+2 f l_{3}+f \pi D_{2}\right] \\
& I_{c}=\frac{f \mu_{0} \pi\left(D_{2}\right)^{2}}{4 L}
\end{aligned}
$$

\section{De.reraters}

1. H. Marder and F. E. Stemon, Los Alavos Scientific Laboratory Report, L-5399-P (1973).

2w. R. Ell1s, Jr., W. B. Rieaenfeld, and C. A. Sanyer, Los Alawos Scientific Laboratory Raport, U-5474-P (1973). 